\title{
Commentary
}

\section{Sustaining Citizen Science beyond an Emergency}

\author{
Cobi Calyx ${ }^{1,2}$ (1) \\ 1 Centre for Social Impact, UNSW Sydney, Sydney 2052, Australia; cobi.calyx@unsw.edu.au \\ 2 Climate and Sustainability Policy Research Group, Flinders University, Adelaide 5042, Australia
}

Received: 27 April 2020; Accepted: 29 May 2020; Published: 2 June 2020

check for updates

\begin{abstract}
This commentary explores lessons learned about aspects of citizen science sustainability, such as open data reuse after a project ends or after the urgency of a disaster. It is framed to be consistent with emerging research about how the 2020 pandemic relates to the sustainable development goals (SDGs). It argues for the importance of open data in citizen science, both in platform design and in citizen science outputs, to support sustainability beyond a funding cycle or emergency. This commentary discusses open datasets developed during the Ebola outbreak response in 2014 and the role of collaborative repositories in enabling uses beyond a single project. How citizen scientists can creatively contribute in ways aligned with humanitarian disaster response aims is explored.
\end{abstract}

Keywords: citizen science; crowdsourcing; PPE; SDGs; emergency response; disaster response; pandemic; open data; open source; sustainability; collaborative learning; disaster response; Ebola; Pybossa; GitHub; public health

\section{Introduction}

Though the world has faced a pandemic in 2020, potentially impeding the sustainable development goals (SDGs), researchers are arguing that it can still be "a year of strengthening global actions to accelerate the transformations required for achieving the 2030 agenda" [1]. Citizen science will be part of these transformations [2]. Though COVID19 has made facing pandemics mainstream, substantial research exists about earlier outbreaks, while global frameworks for navigating disasters can shape responses. This commentary draws on learnings from citizen science and UN responses to the 2014 Ebola outbreak, framed through disaster response and humanitarian aims, to share lessons learned for citizen science aligned with progressing the SDGs.

The 2014 Ebola outbreak in West Africa was the deadliest in history [3]. During the outbreak, an application of an experimental citizen science platform called GeoTag-X was developed at the UN and CERN in Geneva as part of the broader European citizen science research project called Citizen Cyberlab. It was built using the Pybossa open source technology platform to crowdsource imagery analyses for use in humanitarian disaster responses. Most applications were focused on geographic information research, the second-largest type of citizen science after bio-observations; the Ebola instance differed with its primary focus on a third emerging citizen science theme of social sciences and epidemiology [4]. This was developed in response to calls for UN staff internationally to participate in the United Nations Mission for Ebola Emergency Response (UNMEER) as part of a singular UN system-wide approach in response. The Sendai Framework for Disaster Risk Reduction (SFDRR) was established the year afterwards in 2015 [1], so it can only provide a frame for response and analysis in retrospect. There is need for further research linking such disaster response frameworks with health research [5].

The United Nations Security Council (2014) unanimously approved a resolution establishing the UNMEER on 18 September, months into the outbreak [6]. The UNMEER was focused on scaling 
up on-the-ground efforts to contain the outbreak (World Health Organization (WHO) 2015), but this on-the-ground focus was complemented by communication about UNMEER to UN staff in Geneva encouraging people to help in whatever way possible. A module within the citizen science project about the Ebola outbreak was created in response to this UNMEER call to action. Hosted by the UN, the goals of the citizen science initiative aligned strongly with several SDGs, notably SDG 3 about good health and wellbeing, SDG 4 regarding education, SDG 9 on innovation, and SDG 17 about partnerships for the goals.

Given that the UNMEER call to action happened months into the outbreak, the challenges of the Ebola emergency were already established. One of the challenges of the outbreak was the need for on-the-ground medical staff to wear comprehensive personal protective equipment (PPE) to avoid infection themselves. PPE was a challenge, as the amount of coverage required was so comprehensive that some medical staff felt it was a barrier to patient care or was claustrophobic [7]. For people contemplating contributing to disaster response on the ground, PPE access and use was an essential concern. People that were intrinsically motivated to remotely contribute as citizen scientists could help build knowledge and awareness about these on-the-ground concerns $[8,9]$.

The introductory explanation of the citizen science application emphasized that it was experimental and encouraged volunteers to focus their efforts on an emergency needs list issued by UNMEER if they were in a position to contribute to those efforts. It is essential for citizen science applications in disaster response contexts to emphasize that emergency needs must come first. This project was explicitly aimed at remote volunteers otherwise unengaged in response efforts to avoid diverting resources away from established needs. Remote participants can be contrasted with citizen science involving people on the ground of an outbreak, who can yield outcomes such as predicting risks of emerging infectious disease and generating data about infection prevalence [10].

\section{Lessons Learned in Design Related to SDG 9}

The citizen science application was designed to engage volunteers in collecting images from social and traditional media about a particular disaster into a dataset. Methods for how people could participate in the project have been detailed elsewhere [11,12]. There were two ways people could participate: By sourcing relevant image links and adding them into the application via various widgets, or by analyzing these images according to predefined questions or geotagging their location.

Importantly for sustainability, it was made with Pybossa, an open source platform for crowdsourcing. Open science, open data, and open mapping methods are preferred for disaster responses aligned with the SDGs [1]. The data produced were explicitly open data [13,14], consistent with the ideals of the UN and CERN, where it was hosted. Open data are able to be used beyond the life of any given research project and can be used rapidly, without need to clarify permissions, which can be particularly valuable in crowdsourcing for emergency public health contexts. Open source platforms can be considered transborder infrastructures that promote affordable and equitable access for all, a key target of SDG 9 regarding innovation.

Considering open data as a method for citizen science is important-in other cases, assumptions are made that data are openly available in line with motivations of volunteers, when they are not. For example, in the well-established citizen science field of biodiversity observations, researchers found that volunteered data sets are among the most restrictive in how they can be used [15]. These researchers called for organizations managing citizen science data to make their sharing policies open and explicit.

Methods for module design in this open source citizen science platform are open source on GitHub [16,17], and an earlier publication [18] included examples of code for how different types of questions were structured. The underlying open source code had previously been adapted for use in light pollution [19] and forest [20] crowdsourced monitoring projects. CrowdCrafting, a citizen-led online platform powered by Pybossa, was subsequently used in other public health contexts [21].

The "geo" elements of the projects used OpenStreetMap, another open-source, citizen-led initiative with demonstrated potentials for promoting active citizenship [22]. The project was part of a broader 
EU-funded project called Citizen Cyberlab, which included several other citizen science pilot projects based on different code, including, for example, Epicollect+ [23].

Given methods published elsewhere, this commentary focuses on the specifics of the Ebola application that relevant for reuse as well as applications in other disasters. The explanatory text was linked to relevant content on authoritative websites, while explaining that the lack of a cure made full PPE essential. As of 2019, a cure for Ebola has demonstrated success [24], so this framing of language is now historical, but with relevance for emerging and future pandemics.

\section{"Assessing Use of Personal Protective Equipment in Ebola Response Efforts}

The WHO has new protective equipment guidelines in response to the Ebola crisis. There is a PDF showing steps to putting on protective equipment. Since there is no known cure for Ebola, protection from infection is crucial in emergency response. Changes to this guidance in response to Ebola are explained by the CDC (US Centres for Disease Control and Prevention).

This project is part of the Citizen Cyberlab project researching citizen science. It aims to raise awareness of Ebola emergency response efforts and to experiment with using GeoTag-X to support training about personal protective equipment. The results are experimental and do not directly contribute to Ebola response action. The UN has created the first-ever UN emergency health mission for this crisis, which includes a list of what is still needed. If you can contribute to the emergency needs listed by UNMEER, please focus your efforts there first.

Images to begin this project are from Médecins Sans Frontières Australia, UNICEF Liberia, and the International Federation of Red Cross and Red Crescent Societies. Volunteers add new images to the project from other sources, and you can check these sources for licensing information. Here is an explanation of personal protective equipment (PPE) used in Ebola response from Médecins Sans Frontières ..." [25]

This text was followed by an image from Médecins Sans Frontières of a responder dressed in full PPE carrying a child (whose face was not pictured) in one hand and a bag in the other. It was overlaid by information about several pieces of PPE. These included protective goggles, a face mask, protective apron and suit, chemical-resistant gloves, and rubber boots. The linked WHO document referred to in the text above was a guide from the WHO about the 10 steps of putting on PPE for treating viral hemorrhagic fever. Most steps were about putting on the items of PPE, though step eight was about hand hygiene. The first step was about the need for PPE in handling either a suspected, probable, or confirmed case of viral hemorrhagic fever, while the second stated that the dressing and undressing of PPE should be supervised by another trained team member. Though recent progress with a cure [24] and vaccine for Ebola [26] means PPE is not the lifesaving necessity it was during the time of this Citizen Cyberlab experiment, it will take time in emerging and future pandemics to find cures, for which such information may be as relevant [27].

Both the SFDRR and several SDGs, notably 17 regarding partnerships, highlight the need for efforts to link local on-the-ground action with broader responses and systems. How the citizen science application sourced and handled images is an example of this. The citizen science application was seeded with images from organizations involved in responding on the ground to the emergency; the majority were sourced from Flickr, where licensing conditions are made explicit. Clear labeling of Creative Commons licensing or otherwise in repositories facilitates use in disaster contexts. The Pybossa platform displayed the images from their original source provided by the response agencies, and volunteers could click on a link to the image source, allowing them to critically analyze the image and its source and gather more information.

Remote participants were then able to source new images for the project by installing widgets for different browsers, allowing the data analyzed to become "citizen-led", in contrast to citizen science applications in which experts are in control of the dataset to be analyzed. This meant that the first analysis question asked participants to assess whether or not the image displayed was indeed relevant 
to the topic, introducing critical analysis as a foundational thought process for participation. While the concept of "fake news" has recently gone mainstream, problems of misinformation in social media about disasters have been known for years [28]. Embedding critical consideration about whether an image is a genuine novel contribution can be a lesson learned from disaster response for other citizen science contexts.

The platform did not store a database of photos directly; instead, it displayed images via the links created by organizations working on the ground and uploading them to the internet. The module was not a method of uploading new content showing PPE; rather, it generated a dataset of links to images shared by emergency response or news services. This was an asset for sustainability, as it means the open dataset of image and video links remains useful despite the crowdsourcing project no longer existing. It also avoided copyright issues of storing images owned by others. This embedded acknowledgement of sources allowed participants to learn about the diversity of agents in disaster response situations, should they wish to go beyond image analysis to understand the context of the disaster. Embedding opportunities for participants to go beyond the platform and seek out more knowledge and ways of digital volunteering was a method of supporting SDG 17 in design.

\section{Open Access, Open Data, and SDG 10}

Data management matters and has implications for equity of access. SDG 10 aims for social, economic, and political inclusion of all; open data and access align with these aims in theory. In practice, important caveats remain, for example, regarding personal data and Indigenous sovereignty [29,30]. Beyond important caveats, change towards open data aligns well with SDG 17 regarding partnerships, given cases where data are not open due to institutional constraints or lack of foresight, rather than intention to prevent reuse.

An example of an open dataset is highlighted here to introduce a discussion of datasets associated with the 2014 Ebola response on an open source, version-controlled open data sharing site. Though GeoTag-X no longer exists, a dataset was created through it of 26 unique sources of PPE imagery, shown in Table 1, which remain active links as of September 2019. This dataset remains available as open data via GitHub [31]. This is an example of how sharing open data promotes sustainability.

GitHub has been described in Nature as a "democratic database" for scientists [32]. The Nature article described how a researcher in computational epidemiology wanted to model the 2014 Ebola outbreak's spread. Using GitHub [33] allowed it to become a collaborative work with other scientists through updating the daily patient counts and validating the data. This example, combined with the table above, demonstrates within a single emergency the range of disciplines to which crowdsourcing methods and citizen science can apply, from media studies to epidemiology. Furthermore, these examples highlight how open data across platforms can enable new forms of engagement to manifest, controlled by citizens. The dataset in Table 1 [31] was generated on a crowdsourcing platform, then transferred to GitHub to enable other uses. Public health monitoring data were shared by a scientist on GitHub then modified by others, collaborating to generate greater knowledge. Locking data onto any particular citizen science platform limits potentials of active citizenship; opening them enables creative engagement with humanitarian aims.

Both cases raise questions about who are "citizens" and who are "scientists"—-the author was explicitly funded to work on GeoTag-X as part of a research project; however, involvement continued beyond the research funding on a volunteer basis. [33] was a scientist who took the initiative to share data about the spread of Ebola on GitHub, enabling others to collaborate in updating it. Assumptions about participants of citizen science as laypeople providing data that are used by others in an extraction of knowledge may be valid in some cases, but, in other cases, limit understandings of diverse actors and motivators in citizen science and digital volunteering. 
Table 1. Unique URLs linking to content about personal protective equipment (PPE) used in Ebola responses [31].

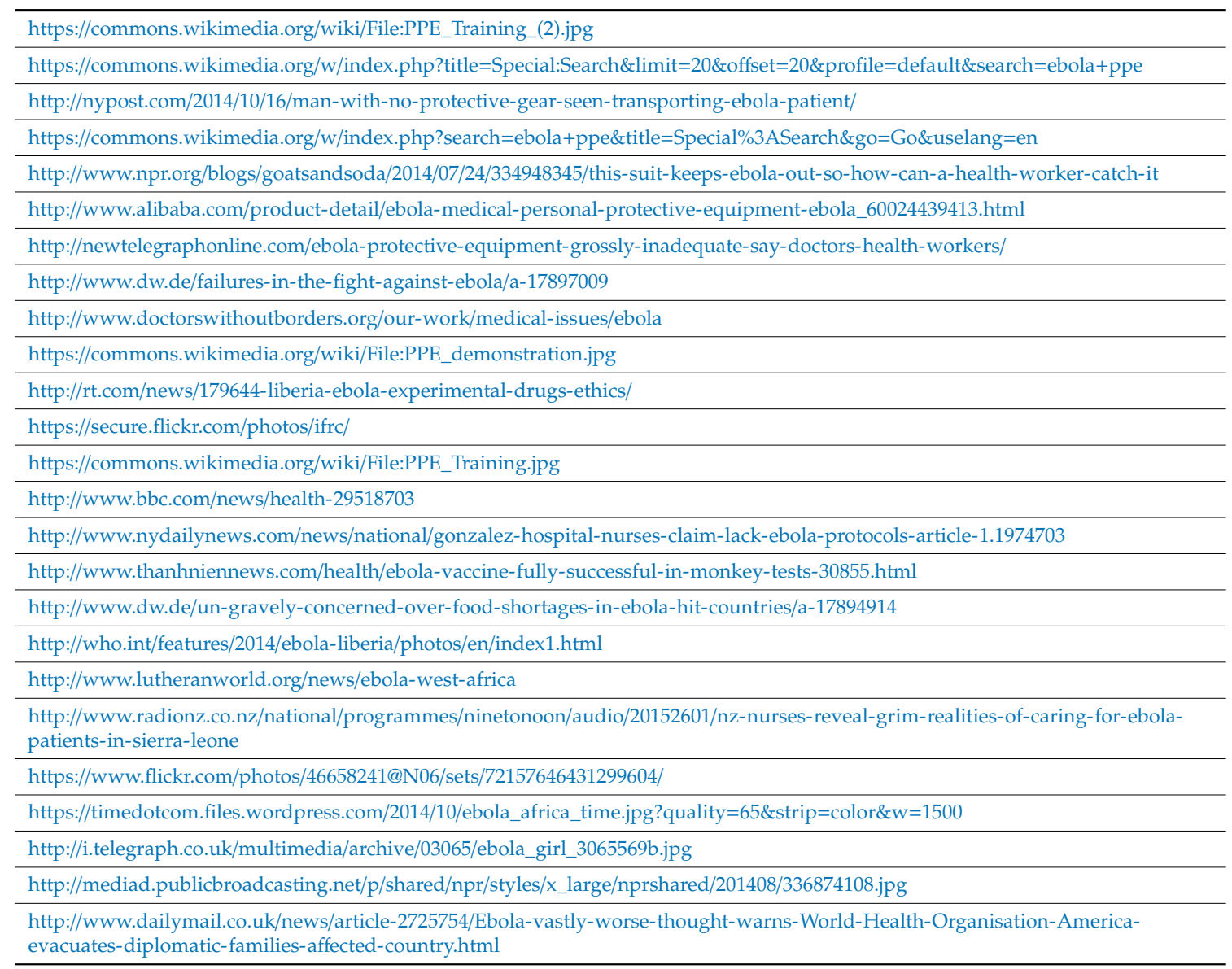

Researchers at CERN concluded that "sharing data is not enough; it is also essential to capture the structured information about the research data analysis workflows and processes to ensure the longevity of results" [13]. The researchers' conclusion referred to the kind of physics data for which CERN is best known; however, it applies as well to citizen science projects aiming for sustainability. This has been a focus of an earlier publication about GeoTag-X [18] and processes in which data shared in publications and reports were also open data shared on GitHub. Because this project was based on the open source Pybossa platform, with bespoke code shared on GitHub, knowledge about analysis workflows and processes can still be accessed despite the end of the research project.

The retirement of the GeoTag-X domain means that the code and data artefacts on GitHub are more important as a primary source. This raises questions about the appropriateness of sharing on GitHub as a foundation for sustainability. GitHub was acquired by Microsoft in 2018, making billionaires in the process [34]. Though GitHub was a company before, its purchase by an infamously profit-driven company whose commitment to openness has been questioned [35] was correlated with a flood of people moving their code to other platforms [36]. Nature reported on scientists' reactions, including sentiments such as "open science is not compatible with one corporation owning the platform used to collaborate on code .... GitHub, as a centralized and closed company, possesses a dangerous level of control over the open-source ecosystem" [37]. This demonstrates how open access and open data can be unpacked at multiple levels relating to SDGs; for example, here, regarding SDG 9 on industry and innovation. Who is profiting from the aggregation of open datasets and are there ways this can be further decentralized, so that people of diverse political and economic backgrounds benefit from hosting open data, not just accessing it? 


\section{Collaborative Learning as SDG 4: Citizen Science Contributing to Education}

An aspect of SDG 4 is ensuring that all learners acquire the knowledge and skills needed to promote sustainable development. For years, researchers have documented how citizen science can contribute to education [38], and, recently, such potential has been linked to SDGs [2]. Given that this existing knowledge is often focused on environmental education, lessons learned regarding how engagement shapes learning are shared here, and are applicable for education across the SDGs related to disaster response.

Interviews with Citizen Cyberlab participants contributed to research that concluded that participants valued opportunities to think creatively and that most creative products were community-related. Researchers argued that "creativity in citizen cyberscience is a collective process: Volunteers create within a project and a community, both for themselves and for others" [12] (p. 101). An important aspect of the GeoTagX project for creativity, not universal within citizen science, was that volunteers could contribute to the design of the projects. Involving participants in the design stages of citizen science projects provides more scope for engagement than projects designed exclusively by a small group, then released for public use.

Given that designing projects in GeoTagX could be in collaboration with participants, documentations from creating the projects were results in themselves, while outputs, such as the earlier table, were further results downstream from the design process. Interviews with GeoTag-X volunteers suggested that, while some were not interested in the technical side of citizen science design, elements of the user interface could be engaging in ways that supported active citizenship.

I think that even people who have not got that much interest in designing their own programs, they still tend to go 'oh why is that question worded in that way? I think that the question should be worded in some other way'. And so I think that it encourages people to strategically think about questions, and to think about how they might choose to word questions differently [ ... ] for example in that Github forum, there are already people saying "I would like to see this question worded that way" and there have been changes to the site based on that ... [12] (pp. 109-110).

The comment above shows that participants did not just see the project as the Pybossa deployment where images were displayed-interactive elements of the GitHub repository enabled discussion and thinking beyond the platform, evidencing how citizen science can extend beyond any given tool or platform to manifest collaborative learning and critical thinking in ways potentially unanticipated or unobserved by those hosting a platform. Even in contexts of more closed, extractive citizen science platforms, contributors are free to discuss their experiences elsewhere, both online and in the real world.

Many "communities of practice" [39] for open science and citizen science exist, arguably because collaborative learning with other people enables participants to gain greater understanding and skills, allowing them to move from peripheral participants to more central ones. The concept of legitimate peripheral participation [40] has been applied to other open communities, such as Wikipedia [41]; the long-tail distribution of participation characteristic of this applied to GeoTag-X [42]. To promote creative engagement through citizen science, designers and coordinators can cultivate opportunities for participants to interact.

The nature of collaborative learning allows participants to derive meaning from their shared or diverse experiences [43] in ways beyond the control of an organizer. While data produced from citizen science may be heavily structured and controlled by the platform host, participants have opportunities to critique and learn in less structured ways through social elements. This can be based on formats ranging from technology-based hackathons [44-46] to nature-based bioblitzes [47,48] — both of which can involve remote participation, but typically are characterized by a shared space of action [49].

During a global health unconference session at OpenCon in Washington on 13 November 2016, this citizen science project was discussed within broader conversations about the potential value of repositories and frameworks for open data in outbreaks. This prompted the author to fork GeoTag-X datasets to their own GitHub account for potential future use related to open public health projects. 
"Forking" and duplicating datasets so they are available from more than one source is characteristic of open methods; it supports sustainability because if one version of the data is deleted, others are available. Forking also allows people to explore data and learn how to contribute to a project without risking "breaking" it or deleting unique knowledge accidentally [50]. The impact of face-to-face participation in the OpenCon community (preceded by participation in other open knowledge communities, such as OpenStreetMap) in forking open public-health-related data evidences the importance of collaborative learning opportunities in the real world linked to citizen science.

\section{From the Ground Up: Does Locality Matter for SDG 9?}

Building resilient infrastructure, promoting inclusive and sustainable industrialization, and fostering innovation are the pillars of SDG 9. Though the targets discuss regional and transborder infrastructure, innovation means that humanity has infrastructure beyond any nation's borders, both in space and online. A lesson learned from this project and its evolutions considers whether such locations matter.

Though GeoTag-X was retired some years after its European Commission FP7 project funding finished, a related H2020 project was funded, called E2mC (Evolution of Emergency Copernicus services). A theme overlapping both projects has been whether digital volunteers can help structure datasets of disaster information in ways useful to emergency responders $[18,42,51,52]$. This thread of research and knowledge is one of several in this field [53], not all of which have explicitly humanitarian goals.

A change in focus from the OpenStreetMap-based GeoTag-X project and the new H2020 E2mC project is that the geodata source has changed to the Copernicus Earth Observation Program of the European Union (EU 2014). OpenStreetMap volunteers are often motivated by a "personal but shared need" [54], which is arguably likewise a motivation for the existence of the EU. Changing focus from the "ground-based" but online community-driven nature of OpenStreetMap to the space-based, institution-driven nature of satellite sensors is notable in the context of considering the power of citizen scientists in a project.

Citizen science in disaster response can be approached with sustainable development and digital humanitarian mindsets [18] with open code; it can also be considered from security or defense perspectives [55] and using closed platforms [56]. If citizen science in disaster contexts aims to improve state responses to citizens' needs, then authorities' involvement in citizen science is implied in organizing or interpreting data in ways used by emergency response authorities. Issues of ownership and control are not unique to situations involving expensive technology endeavors, such as satellites-researchers analyzing citizen science biodiversity observations found that data were often not open as might be expected by those volunteering [15].

State or corporate outcomes are not necessarily at the expense of citizens' active engagement, if design and data collection methods enable citizens to use and discuss data creatively rather than seek to retain power over frames [57] and outcomes. Useful outcomes for funders, such as governments or science organizations, are important for sustainability [58]. The nature of open data is to accommodate multiple uses, so use of open data is a strategy to accommodate both intended outcomes and unexpected ones. This reflects broader trends towards citizen engagement in governance in our information age, about which ample literature exists [59].

Researchers have highlighted how citizen science data can enhance SDG measurement [2], arguing that the quality of data from citizen science can be evaluated using the same measures as for any other official data. This considers data quality from the perspective of prospective users-it is also important to consider the data creators and alignment with SDGs, such as those with targets for empowering women or increasing participatory governance in developing countries. In replacing community-led initiatives with data generated by machines, whether satellites or artificial intelligence [60], there are implications for other SDGs beyond those for which measurement is enhanced. 


\section{First Responders in Times of Change: SDG 13 and Converging Crises}

Who are "emergency responders"? Salaried emergency responders are typically employed by governments; for example, firefighters and paramedics. Like citizen science, effective emergency responses typically rely on a combination of paid professional and volunteer efforts. While the Citizen Cyberlab project described participants as citizen scientists, within crisis informatics research, the same participants may be described as everyday analysts [61] or first responders [62]. All terminologies reflect the importance of meaningful participation and valuing local knowledge, alongside that of experts [18].

By viewing the citizenry as a powerful, self-organizing, and collectively intelligent force, information communications technology (ICT) has the potential to play a remarkable and transformational role in the way society responds to mass emergencies and disaster. Furthermore, this view of a civil society that can be augmented by ICT is based on social and behavioral knowledge about how people truly respond in disaster, rather than on simplified and mythical portrayals of people unable to help themselves. Research has shown that disaster victims themselves are the true first responders, frequently acting on the basis of knowledge not available to officials [62] (pp. 1-2).

First responders, as a category of emergency responders, have some proximal relationship to an emergency. Most obviously, this is physical location [63]; however, digital technologies enable different types of volunteering [64], such as remote volunteers in citizen science.

Thus far, this commentary has presented citizen science in emergency responses as focused within geographical and public health fields, rather than the largest citizen science field of biology observations [4]. In this era of the long-term disaster that is climate change and more extreme weather events, this division is increasingly trivial. SDG 13 calls for action on climate change, relating targets to climate-related hazards. Other GeoTag-X applications beyond the PPE module explored drought and floods, in some cases asking volunteers to identify or analyze biological elements within disaster imagery. The conceptual frame of OneHealth integrates observations of human, animal, and environmental factors - this can be usefully applied to citizen science. Though recent decades' citizen science efforts may have had a particular focus for observations and analyses, in future decades, emergent understandings could be derived from linking datasets and tracking observations over time and space in unanticipated ways. Social science analyses of the different ownership and participation structures in citizen science could generate open datasets that may, in turn, support reuse in addressing wicked problems.

\section{Conclusions}

Reflecting on a retired citizen science project provides lessons learned for sustainability. These reflections are framed in the context of SDGs, global frameworks, and how these intersect with the 2020 pandemic, drawing on an example about PPE in the 2014 Ebola response. A crosscutting theme is the value of open data and methods for enabling participants to creatively contribute in the design, collection, and interpretation phases. In open data contexts where no authority gives permission for use, first responders can quickly access and repurpose data for disaster responses aligned with SDGs. Original citizen science data collection is typically driven with a particular outcome in mind, often defined in a distinct field, such as conservation or epidemiology. Such drivers are compatible with further uses aligned with progressing SDGs if sustainability is considered in the design and embedded in the methods.

Funding: These lessons learned emerged from a project funded through the European Commission FP7-ICT project "Citizen Cyberlab: Technology Enhanced CreativeLearning in the field of Citizen Cyberscience".

Acknowledgments: This research was underpinned by the work of the Pybossa development team, particularly Daniel Lombraña. The work of Lars Bromley and Eleanor Cervigni at UNOSAT on earlier GeoTag-X projects paved the way for the Ebola one. Thanks to Francois Grey from UNIGE for support and leadership in the Citizen 
Cyberlab research project. Thanks to the volunteers who contributed to GeoTag-X by collecting and analyzing images. Thanks to the OpenCon community for inspiration and motivation for documenting these lessons learned.

Conflicts of Interest: The authors declare no conflict of interest.

\section{References}

1. Djalante, R.; Shaw, R.; DeWit, A. Building resilience against biological hazards and pandemics: COVID-19 and its implications for the Sendai Framework. Prog. Disaster Sci. 2020. [CrossRef]

2. Fritz, S.; See, L.; Carlson, T.; Haklay, M.M.; Oliver, J.L.; Fraisl, D.; Mondardini, R.; Brocklehurst, M.; Shanley, L.A.; Schade, S.; et al. Citizen science and the United Nations Sustainable Development Goals. Nat. Sustain. 2019, 2, 922-930. [CrossRef]

3. Sharareh, N.; Sabounchi, N.S.; Sayama, H.; MacDonald, R. The Ebola crisis and the corresponding public behavior: A system dynamics approach. PLoS Curr. 2016. Available online: https://www.ncbi.nlm.nih.gov/ pmc/articles/PMC5118047/ (accessed on 1 June 2020).

4. Kullenberg, C.; Kasperowski, D. What is citizen science?-A scientometric meta-analysis. PLoS ONE 2016, 11, e0147152. [CrossRef] [PubMed]

5. Chan, E.Y.; Murray, V. What are the health research needs for the Sendai Framework? Lancet 2017, 390, e35-e36. [CrossRef]

6. Boozary, A.S.; Farmer, P.E.; Jha, A.K. The Ebola outbreak, fragile health systems, and quality as a cure. JAMA 2014, 312, 1859-1860. [CrossRef]

7. Gershon, R.; Dernehl, L.A.; Nwankwo, E.; Zhi, Q.; Qureshi, K. Experiences and psychosocial impact of West Africa Ebola deployment on US health care volunteers. PLoS Curr. 2016. [CrossRef]

8. Tinati, R.; Luczak-Roesch, M.; Simperl, E.; Hall, W. An investigation of player motivations in Eyewire, a gamified citizen science project. Comput. Hum. Behav. 2017, 73, 527-540. [CrossRef]

9. Phillips, C.; Walshe, D.; O’Regan, K.; Strong, K.; Hennon, C.; Knapp, K.; Murphy, C.; Thorne, P. Assessing citizen science participation skill for altruism or university course credit: A case study analysis. Citiz. Sci. Theory Pract. 2018, 3, 6. [CrossRef]

10. Curtis-Robles, R.; Wozniak, E.J.; Auckland, L.D.; Hamer, G.L.; Hamer, S.A. Combining public health education and disease ecology research: Using citizen science to assess Chagas disease entomological risk in Texas. PLoS Negl. Trop. Dis. 2015, 9, e0004235. [CrossRef]

11. Jennett, C.; Kloetzer, L.; Schneider, D.; Iacovides, I.; Cox, A.; Gold, M.; Fuchs, B.; Eveleigh, A.; Methieu, K.; Ajani, Z.; et al. Motivations, learning and creativity in online citizen science. J. Sci. Commun. 2016. [CrossRef]

12. Jennett, C.; Kloetzer, L.; Cox, A.L.; Schneider, D.; Collins, E.; Fritz, M.; Bland, M.J.; Regalado, C.; Marcus, I.; Stockwell, H.; et al. Creativity in Citizen Cyberscience. Hum. Comput. 2016, 3, 101-104. [CrossRef]

13. Chen, X.; Dallmeier-Tiessen, S.; Dasler, R.; Feger, S.; Fokianos, P.; Gonzalez, J.B.; Rodriguez, D.R. Open is not enough. Nat. Phys. 2018, 15, 113-119. [CrossRef]

14. Laessig, M.; Jacob, B.; AbouZahr, C. Opening Data for Global Health. In The Palgrave Handbook of Global Health Data Methods for Policy and Practice; Palgrave Macmillan: London, UK, 2019; pp. 451-468.

15. Groom, Q.; Weatherdon, L.; Geijzendorffer, I.R. Is citizen science an open science in the case of biodiversity observations? J. Appl. Ecol. 2017, 54, 612-617. [CrossRef]

16. GitHub-Cobismith/geotagx-project-ebola. Available online: https://github.com/cobismith/geotagx-projectebola (accessed on 2 June 2020).

17. Geotag-X. Available online: https://github.com/geotagx/ (accessed on 2 June 2020).

18. Smith, C. A Case Study of Crowdsourcing Imagery Coding in Natural Disasters. In Data Analytics in Digital Humanities; Springer: Berlin/Heidelberg, Germany, 2017; pp. 217-230.

19. Navas, R.; Lombrana, D. Collaborative georeference of ISS night images for light pollution and energy consumption studies. In Proceedings of the Jornadas Ibéricas de Infra-estruturas de Dados Espaciais (Iberian Conference on Spatial Data Infrastructures), Lisbon, Portugal; 2014. Available online: http://docplayer.net/20860581-Collaborative-georreference-of-iss-night-images-for-light-pollutionand-energy-consumption-studies.html (accessed on 2 June 2020).

20. Luz, E.F.; Correa, F.R.; González, D.L.; Grey, F.; Ramos, F.M. The forestwatchers: A citizen cyberscience project for deforestation monitoring in the tropics. Hum. Comput. 2014, 1, 137-145. 
21. Di Pasquale, A.; McCann, R.S.; Maire, N. Assessing the population coverage of a health demographic surveillance system using satellite imagery and crowd-sourcing. PLoS ONE 2017, 12, e0183661. [CrossRef]

22. Arsanjani, J.J.; Zipf, A.; Mooney, P.; Helbich, M. An introduction to OpenStreetMap in Geographic Information Science: Experiences, research, and applications. In OpenStreetMap in GIScience; Springer: Cham, Switzerland, 2015; pp. 1-15.

23. Aanensen, D.M.; Huntley, D.M.; Feil, E.J.; Spratt, B.G. EpiCollect: Linking smartphones to web applications for epidemiology, ecology and community data collection. PLoS ONE 2009, 4, e6968. [CrossRef]

24. Dyer, O. Two Ebola treatments halve deaths in trial in DRC outbreak. BMJ 2019, 366, 15140. [CrossRef]

25. Cobismith/geotagx-project-ebola. Available online: https://github.com/cobismith/geotagx-project-ebola/ blob/master/long_description.md (accessed on 2 June 2020).

26. Cohen, J. Ebola outbreak continues despite powerful vaccine. Science 2019, 364, 223.

27. Oppenheim, B.; Gallivan, M.; Madhav, N.K.; Brown, N.; Serhiyenko, V.; Wolfe, N.D.; Ayscue, P. Assessing global preparedness for the next pandemic: Development and application of an Epidemic Preparedness Index. BMJ Glob. Health 2019, 4, e001157. [CrossRef]

28. Gupta, H.; Lamba, P.; Kumaraguru, A. Joshi, Faking Sandy: Characterizing and identifying fake images on Twitter during Hurricane Sandy. In Proceedings of the 22nd International Conference on World Wide Web Companion, Rio de Janeiro, Brazil, 13-17 May 2013; pp. 729-736.

29. Taylor, J.; Kukutai, T. Indigenous Data Sovereignty: Toward an Agenda; ANU Press: Canberra, Australia, 2016.

30. Beaton, A.; Hudson, M.; Milne, M.; Port, R.V.; Russell, K.; Smith, B.; Toki, V.; Uerata, L.; Wilcox, P.; Bartholomew, K.; et al. Engaging Māori in biobanking and genomic research: A model for biobanks to guide culturally informed governance, operational, and community engagement activities. Genet. Med. 2017, 19, 345-351. [CrossRef] [PubMed]

31. GeoTag-X-Project-Ebola/Uniquesources.csv. 2018. Available online: https://github.com/cobismith/GeoTag-Xproject-ebola/ (accessed on 2 September 2019).

32. Perkel, J. Democratic databases: Science on GitHub. Nat. News 2016, 538, 127. [CrossRef]

33. Rivers, C. Cmrivers/Ebola. 2018. Available online: https://github.com/cmrivers/ebola (accessed on 2 September 2019).

34. Kirsch, N. Microsoft's Acquisition of GitHub Mints New Billionaires. 2018. Available online: https://www. forbes.com/sites/noahkirsch/2018/06/04/github-acquisition-mints-new-billionaires/\#6138810c3c75 (accessed on 6 September 2019).

35. Dann, G.E.; Haddow, N. Just doing business or doing just business: Google, Microsoft, Yahoo! and the business of censoring China's Internet. J. Bus. Ethics 2008, 79, 219-234. [CrossRef]

36. Hall, C. Why Open Source Software is Moving to GitLab After Microsoft-GitHub Deal. IT Pro Today. 2018. Available online: https:/www.itprotoday.com/linux/why-open-source-software-moving-gitlab-aftermicrosoft-github-deal (accessed on 6 September 2019).

37. Silver, A. Microsoft's purchase of GitHub leaves some scientists uneasy. Nature 2018, 558, 353-354. [CrossRef] [PubMed]

38. Mueller, M.P.; Tippins, D.J. Citizen science, ecojustice, and science education: Rethinking an education from nowhere. In Second International Handbook of Science Education; Springe: Dordrecht, The Netherlands, 2012; pp. 865-882.

39. Wenger, E. Communities of practice: Learning as a social system. Syst. Think. 1998, 9, 2-3. [CrossRef]

40. Lave, J.; Wenger, E. Situated Learning: Legitimate Peripheral Participation; Cambridge University Press: Cambridge, UK, 1991.

41. Halfaker, A.; Keyes, O.; Taraborelli, D. Making peripheral participation legitimate: Reader engagement experiments in Wikipedia. In Proceedings of the 2013 Conference on Computer Supported Cooperative Work, February 2013; Available online: http://citeseerx.ist.psu.edu/viewdoc/download?doi=10.1.1.726.3932\& rep $=$ rep1\&type $=$ pdf (accessed on 2 June 2020).

42. Cervigni, E.; Smith, C. Learning Modules on Media Interpretation and Disaster Response Data Generation. Citizen Cyberlab Report. 2014. Available online: https://osf.io/6n9mx/ (accessed on 6 September 2019).

43. Dillenbourg, P. What do you mean by collaborative learning? In Collaborative Learning: Cognitive and Computational Approaches; Elsevier: Oxford, UK, 1999; pp. 1-19.

44. Irani, L. Hackathons and the making of entrepreneurial citizenship. Sci. Technol. Hum. Values 2015, 40, 799-824. [CrossRef] 
45. Lara, M.; Lockwood, K. Hackathons as community-based learning: A case study. TechTrends 2016, 60, 486-495. [CrossRef]

46. Kienzler, H.; Fontanesi, C. Learning through inquiry: A global health hackathon. Teach. High. Educ. 2017, 22, 129-142. [CrossRef]

47. Baker, G.M.; Duncan, N.; Gostomski, T.; Horner, M.A.; Manski, D. The bioblitz: Good science, good outreach, good fun. Park Sci. 2014, 31, 39-45.

48. Leong, K.M.; Kyle, G.T. Engaging park stewards through biodiversity discovery: Social outcomes of participation in bioblitzes. Park Sci. 2014, 31, 106-111.

49. Briscoe, G.; Virani, T.E.; Dima, M. Hackathons: Why Co-location? Creativeworks London Working Papers; 2015; Available online: https://core.ac.uk/download/pdf/30697213.pdf (accessed on 1 June 2020).

50. Rastogi, A.; Nagappan, N. Forking and the Sustainability of the Developer Community Participation-An Empirical Investigation on Outcomes and Reasons. In Proceedings of the 2016 IEEE 23rd International Conference on Software Analysis, Evolution, and Reengineering (SANER), Suita, Japan, 14-18 March 2016; Volume 1, pp. 102-111.

51. Havas, C.; Resch, B.; Francalanci, C.; Pernici, B.; Scalia, G.; Fernandez-Marquez, J.; Van Achte, T.; Zeug, G.; Mondardini, M.R.; Kirsch, B.; et al. E2mC: Improving emergency management service practice through social media and crowdsourcing analysis in near real time. Sensors 2017, 17, 2766. [CrossRef]

52. Fernandez-Marquez, J.L.; Francalanci, C.; Mohanty, S.; Mondardini, R.; Pernici, B.; Scalia, G. E2mC: Improving Rapid Mapping with Social Network Information. In Organizing for the Digital World; Springer: Cham, Switzerland, 2019; pp. 63-74.

53. Haworth, B.; Bruce, E. A review of volunteered geographic information for disaster management. Geogr. Compass 2015, 9, 237-250. [CrossRef]

54. Budhathoki, N.R.; Haythornthwaite, C. Motivation for open collaboration: Crowd and community models and the case of OpenStreetMap. Am. Behav. Sci. 2013, 57, 548-575. [CrossRef]

55. Comfort, L.K.; Waugh, W.L.; Cigler, B.A. Emergency management research and practice in public administration: Emergence, evolution, expansion, and future directions. Public Adm. Rev. 2012, 72, 539-547. [CrossRef]

56. Rogstadius, J.; Vukovic, M.; Teixeira, C.A.; Kostakos, V.; Karapanos, E.; Laredo, J.A. CrisisTracker: Crowdsourced social media curation for disaster awareness. IBM J. Res. Dev. 2013, 57, 4:1-4:13. [CrossRef]

57. Lieberoth, A.; Kock Pedersen, M.; Sherson, J. Play or science? A study of learning and framing in crowdscience games. Well Played. 2015, 4, 430-455.

58. Parrish, J.K.; Burgess, H.; Weltzin, J.F.; Fortson, L.; Wiggins, A.; Simmons, B. Exposing the science in citizen science: Fitness to purpose and intentional design. Integr. Comp. Biol. 2018, 58, 150-160. [CrossRef]

59. Soma, K.; Termeer, C.J.; Opdam, P. Informational governance-A systematic literature review of governance for sustainability in the Information Age. Environ. Sci. Policy 2016, 56, 89-99. [CrossRef]

60. Ceccaroni, L.; Bibby, J.; Roger, E.; Flemons, P.; Michael, K.; Fagan, L.; Oliver, J.L. Opportunities and Risks for Citizen Science in the Age of Artificial Intelligence. Citiz. Sci. Theory Pract. 2019. [CrossRef]

61. Palen, L.; Vieweg, S.; Anderson, K.M. Supporting "everyday analysts" in safety-and time-critical situations. Inf. Soc. 2010, 27, 52-62. [CrossRef]

62. Palen, L.; Anderson, K.M.; Mark, G.; Martin, J.; Sicker, D.; Palmer, M.; Grunwald, D. A vision for technology-mediated support for public participation \& assistance in mass emergencies \& disasters. In Proceedings of the 2010 ACM-BCS Visions of Computer Science Conference; 2010. Available online: https://dl.acm.org/doi/10.5555/1811182.1811194 (accessed on 1 June 2020).

63. Twigg, J.; Mosel, I. Emergent groups and spontaneous volunteers in urban disaster response. Environ. Urban. 2017, 29, 443-458. [CrossRef]

64. McLennan, B.; Whittaker, J.; Handmer, J. The changing landscape of disaster volunteering: Opportunities, responses and gaps in Australia. Nat. Hazards 2016, 84, 2031-2048. [CrossRef]

(C) 2020 by the author. Licensee MDPI, Basel, Switzerland. This article is an open access article distributed under the terms and conditions of the Creative Commons Attribution (CC BY) license (http://creativecommons.org/licenses/by/4.0/). 